\title{
Detection of Microglial Activation in an Acute Model of Neuroinflammation Using PET and Radiotracers ${ }^{11} \mathrm{C}-(R)-$-PK11195 and ${ }^{18}$ F-GE-180
}

\author{
Alex M. Dickens ${ }^{1,2}$, Susanne Vainio ${ }^{2}$, Päivi Marjamäki ${ }^{2}$, Jarkko Johansson ${ }^{3}$, Paula Lehtiniemi ${ }^{4}$, Johanna Rokka ${ }^{4}$, \\ Juha Rinne $^{3}$, Olof Solin ${ }^{4}$, Merja Haaparanta-Solin ${ }^{2}$, Paul A. Jones ${ }^{5}$, William Trigg ${ }^{5}$, Daniel C. Anthony ${ }^{6}$, and Laura Airas ${ }^{7}$ \\ ${ }^{I}$ Department of Pharmacology, Drug Development and Therapeutics, University of Turku, Turku, Finland; ${ }^{2}$ MediCity/PET Preclinical \\ Laboratory, University of Turku, Turku, Finland; ${ }^{3}$ Turku PET Centre, University of Turku, Turku, Finland; ${ }^{4}$ Radiopharmaceutical \\ Chemistry Laboratory, University of Turku, Turku PET Centre, Turku, Finland; ${ }^{5}$ GE Healthcare Ltd., Amersham, United Kingdom; \\ ${ }^{6}$ Department of Pharmacology, University of Oxford, Oxford, United Kingdom; and ${ }^{7}$ Department of Neurology, Turku University \\ Hospital, Turku, Finland
}

It remains unclear how different translocator protein (TSPO) ligands reflect the spatial extent of astrocyte or microglial activation in various neuroinflammatory conditions. Here, we use a reproducible lipopolysaccharide (LPS)-induced model of acute central nervous system inflammation to compare the binding performance of a new TSPO ligand ${ }^{18} \mathrm{~F}-\mathrm{GE}-180$ with ${ }^{11} \mathrm{C}-(R)$-PK11195. Using immunohistochemistry, we also explore the ability of the TSPO ligands to detect activated microglial cells and astrocytes. Methods: Lewis rats $(n=30)$ were microinjected with LPS $(1$ or $10 \mu \mathrm{g})$ or saline $(1 \mu \mathrm{L})$ into the left striatum. The animals were imaged in vivo at $16 \mathrm{~h}$ after the injection using PET radiotracers ${ }^{18} \mathrm{~F}-\mathrm{GE}-180$ or ${ }^{11} \mathrm{C}-(R)-\mathrm{PK} 11195$ ( $n=3$ in each group) and were killed afterward for autoradiography of the brain. Immunohistochemical assessment of OX-42 and glial fibrillary acidic protein (GFAP) was performed to identify activated microglial cells and reactive astrocytes. Results: In vivo PET imaging revealed an increase in the ipsilateral TSPO binding, compared with binding in the contralateral hemisphere, after the microinjection of $10 \mu \mathrm{g}$ of LPS. No increase was observed with vehicle. By autoradiography, the TSPO radiotracer binding potential in the injected hemisphere was increased after striatal injection of 1 or $10 \mu \mathrm{g}$ of LPS. However, the significant increase was observed only when using ${ }^{18} \mathrm{~F}-\mathrm{GE}-180$. The area of CD11b-expressing microglial cells extended beyond that of enhanced GFAP staining and mapped more closely to the extent of ${ }^{18} \mathrm{~F}-\mathrm{GE}-180$ binding than to ${ }^{11} \mathrm{C}-(R)-$ PK11195 binding. The signal from either PET ligand was significantly increased in regions of increased GFAP immunoreactivity and OX-42 colocalization, meaning that the presence of both activated microglia and astrocytes in a given area leads to increased binding of the TSPO radiotracers. Conclusion: ${ }^{18} \mathrm{~F}-\mathrm{GE}-180$ is able to reveal sites of activated microglia in both gray and white matter. However, the signal is increased by the presence of activated astrocytes. Therefore, ${ }^{18} \mathrm{~F}-\mathrm{GE}-180$ is a promising new fluorinated longerhalf-life tracer that reveals the presence of activated microglia in a manner that is superior to ${ }^{11} \mathrm{C}-(R)-\mathrm{PK} 11195$ due to the higher binding potential observed for this ligand.

Received May 31, 2013; revision accepted Oct. 24, 2013.

For correspondence or reprints contact: Alex Dickens, Department of Pharmacology, Itäinen Pitkäkatu 4 B, University of Turku, 20520 Turku, Finland.

E-mail: alex.dickens@utu.fi

Published online Feb. 10, 2014

COPYRIGHT (C 2014 by the Society of Nuclear Medicine and Molecular Imaging, Inc.
Key Words: neuroinflammation; positron emission tomography; second-generation TSPO ligand; brain; astrocyte

J Nucl Med 2014; 55:466-472

DOI: 10.2967/jnumed.113.125625

$\mathbf{T}$ here is an unmet need for imaging agents that reveal the spatial extent of inflammation in the brain $(1,2)$. The peripheral benzodiazepine receptor, now known as the $18-\mathrm{kDa}$ translocator protein (TSPO), is a cholesterol-transporter protein expressed in the membrane of mitochondria of cells throughout the body (3). The basal expression of TSPO within the brain is low; however, its expression on microglial cells and on astrocytes increases after brain injury and inflammation (4). Because of this expression profile, TSPO has been suggested as a surrogate marker for neuroinflammation (5). The first TSPO PET radiotracer developed was the ${ }^{11} \mathrm{C}$-labeled tracer ${ }^{11} \mathrm{C}-(R)-\mathrm{PK} 11195\left({ }^{11} \mathrm{C}-N\right.$-methyl- $N$-[1-methylpropyl]-1-[2chlorophenyl]-isoquinoline-3-carboxamide, Fig. 1), which has been used to image the increase in TSPO expression in vivo (6). However, there are several problems with ${ }^{11} \mathrm{C}-(R)$-PK11195 that have prevented it from being adopted widely in the clinic. The compound is highly lipophilic $\left(\log \mathrm{D}_{7.4}\right.$ [octanol-water distribution constant at $\mathrm{pH} 7.4]=4.58$ ), leading to binding to fatty structures within the brain. Thus, it has a poor signal-to-noise ratio and is not selective $(7,8)$. The requirement of an on-site cyclotron also limits widespread use. To overcome these shortcomings, novel TSPO ligands have been developed (9). ${ }^{18}$ F-GE-180 ( $S$ - $N, N$-diethyl-9-[2-18 F-fluoroethyl]-5methoxy 2,3,4,9-tetrahydro-1H-carbazole-4-carboxamide, Fig. 1) is the lead compound from a new series of tricyclic indoles, which have been shown to have a high affinity for TSPO (10). According to a preliminary in vitro and biodistribution study, ${ }^{18} \mathrm{~F}-\mathrm{GE}-180$ has shown higher selectivity for TSPO than ${ }^{11} \mathrm{C}-\mathrm{PK} 11195$ (10). However, no direct comparison has been made of the relative sensitivities of these 2 different TSPO radiotracers in a proven model of neuroinflammation.

Here, we sought to compare the binding of ${ }^{18} \mathrm{~F}-\mathrm{GE}-180$ with ${ }^{11} \mathrm{C}-\mathrm{PK} 11195$ in a model of neuroinflammation that involves the activation of both the microglia (11) and the astrocytes (12). Although the binding properties of several novel TSPO radiotracers have been reported in the literature $(2,9)$, it is still unclear which 


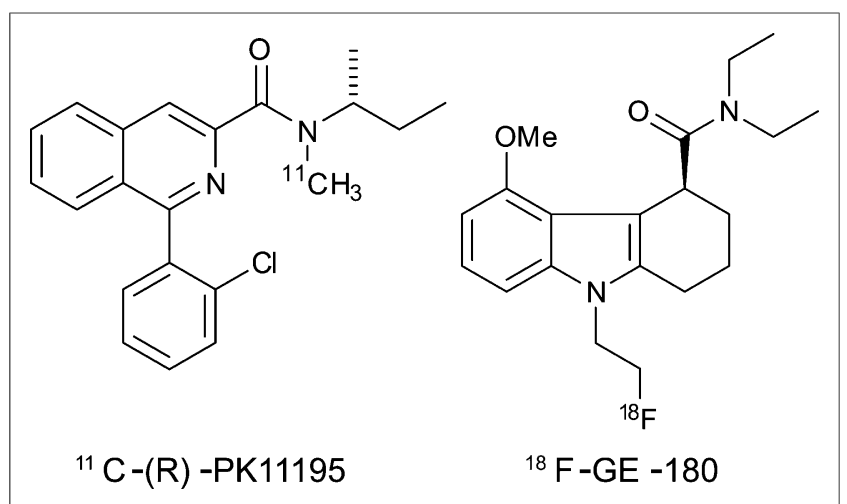

FIGURE 1. Chemical structures of the 2 radiotracers, ${ }^{11} \mathrm{C}-(R)-\mathrm{PK} 11195$ and ${ }^{18} \mathrm{~F}-\mathrm{GE}-180$.

cell populations are responsible for the TSPO binding in response to brain injury. Historically, the increase in TSPO expression was attributed to the activation of the microglia within the central nervous system (13). However, there is now growing evidence that reactive astrocytes also show an increase in TSPO binding after brain insult $(2,14)$. The specificity of TSPO tracers needs to be explored to determine their suitability as surrogate markers for neuroinflammation. In this article, we have performed in vivo PET imaging using both ${ }^{11} \mathrm{C}-(R)$-PK11195 and ${ }^{18} \mathrm{~F}-\mathrm{GE}-180$ in conjunction with ex vivo autoradiography and immunohistochemistry. As such, we demonstrate the relationship between the extent of activation of both microglial cells and astrocytes assessed by immunohistochemistry and the area of binding of each TSPO ligand after autoradiography.

\section{MATERIALS AND METHODS}

\section{Tracer Production}

${ }^{11} \mathrm{C}-(R)$-PK11195 and ${ }^{18} \mathrm{~F}-\mathrm{GE}-180$ were synthesized according to methods first described by Hashimoto (15), Shah et al. (16), and Wadsworth et al. (10), with some modifications (the supplemental methods provide details; supplemental materials are available at http://jnm.snmjournals. org).

\section{Animals}

Adult male Lewis rats (3-4 mo, $n=30$ ) were obtained from Harlan and housed in accordance with the Amsterdam protocol for animal experiments (17). The animals were divided randomly into 2 sets. Animals in set $\mathrm{A}(n=18)$ were used for the ex vivo and in vitro autoradiography experiments. The animals in set $\mathrm{B}(n=12)$ were used in the in vivo experiments (Supplemental Fig. 1). All animal experiments were performed with ethical approval from the Finnish Animal Experiment Board, application number ESAVI/6360/04.10.03/2011. Animals were anesthetized using isoflurane (Baxter Medical $\mathrm{AB}$ ) at $3 \%$ in air or oxygen, and body temperature was maintained using an electronic heating blanket. During the procedure, anesthesia was maintained at $2.5 \%$ in air.

\section{Intrastriatal Injection}

The animals were injected intrastriatally with lipopolysaccharide (LPS) using the method previously described by Serres et al. (18) (the supplemental methods provide more details).

\section{Digital Autoradiography}

Rats from set A were killed for autoradiography analysis $16 \mathrm{~h}$ after the injection of LPS ( $n=3$ per group, groups consisted of rats injected with LPS [10 or $1 \mu \mathrm{g} / \mu \mathrm{L}$ ] or saline). The digital autoradiography was performed as previously described by Forsback et al. (19) (the supplemental methods provide more details).

\section{In Vitro Blocking Studies}

Coronal brain sections ( 20 or $40 \mu \mathrm{m}$ thick) from rats in set A were cryocut and preincubated for $30 \mathrm{~min}$ at room temperature in $50 \mathrm{mM}$ Tris- $\mathrm{HCl}\left(\mathrm{pH} 7.4\right.$ at $25^{\circ} \mathrm{C}$ ) before incubation for $30 \mathrm{~min}$ with ${ }^{11} \mathrm{C}-(R)$ PK11195 (0.67 MBq, $\sim 50 \mathrm{pM})$ or ${ }^{18} \mathrm{~F}-\mathrm{GE}-180(0.42 \mathrm{MBq}, \sim 50 \mathrm{pM})$. The binding specificity for ${ }^{11} \mathrm{C}-(R)$-PK11195 or ${ }^{18} \mathrm{~F}-\mathrm{GE}-180$ was determined by the addition of the unlabeled GE-180 or PK11195 (90 nM), respectively. The sections were washed with ice-cold Tris-buffer and rinsed in ice-cold distilled water to remove buffer salts. The slides were dried under a stream of air at room temperature, exposed to the imaging plate and imaged as described above.

\section{Autoradiography Data Analyses}

Regions of interest (ROIs) were drawn in the left and right striatal and cortical areas on the images obtained from the autoradiography. The digital images were analyzed for count densities (photostimulated luminescence per unit area, PSL $/ \mathrm{mm}^{2}$ ) with Aida 2D Analysis (Raytest Isotopenmessgeräte $\mathrm{GmbH})$. To quantify the binding potential $\left(\mathrm{BP}_{\text {ex vivo }}\right)$ of the radiotracer, the following calculation was performed:

$$
\begin{aligned}
\mathrm{BP}_{\text {exvivo }}= & \left(\left(\mathrm{PSL} / \mathrm{mm}^{2}\right)_{(\text {Lesion })}-\left(\mathrm{PSL} / \mathrm{mm}^{2}\right)_{(\text {Contralateral })}\right) / \\
& \left(\mathrm{PSL} / \mathrm{mm}^{2}\right)_{(\text {Contralateral })}
\end{aligned}
$$

Each result was averaged across the whole striatum to get an overall $\mathrm{BP}_{\text {ex vivo }}$ for each injected animal. To validate the use of the contralateral hemisphere as an appropriate reference region, the binding ratio (BR) of this area was calculated in each animal using an ROI drawn in the cerebellum as a reference region.

\section{In Vivo Imaging}

For the comparison between the 2 different radiotracers, the animals in set B ( $n=3$ for each group, $10 \mu \mathrm{g}$ of LPS, $1 \mu \mathrm{g}$ of LPS, and saline) were imaged $16 \mathrm{~h}$ after the intracerebral injection of LPS (the supplemental methods provide more details).

\section{In Vivo Data Analysis}

The PET data were analyzed as previously described by Farde et al. (20) with some modifications (supplemental methods). The following calculation was performed to determine the binding potential of the ligands:

$$
\mathrm{BP}_{\text {invivo }}=\left(\mathrm{TAC}_{(\text {Lesion })}-\mathrm{TAC}_{(\text {Contralateral })}\right) / \mathrm{TAC}_{(\text {Contralateral })}
$$

\section{Pixelwise Modeling of In Vivo Images}

The dynamic datasets were aligned to a standard T2 MR imaging template with PMOD (PMOD Technologies Ltd.) using the inbuilt rigid body-matching tool in the fusion package. Spheric volumes of interest were once again placed in the contralateral hemisphere. These volumes of interest were used to perform the pixelwise calculation of the binding potential during the period of maximal binding (25-50 min). These calculations were performed in Matlab (R2011a; The MathWorks). Further manipulations of the resultant images (averaging and subtraction) were performed in Statistical Parametric Mapping version 8 (SPM 8; Wellcome Trust Centre for Neuroimaging).

\section{Immunohistochemical Analysis}

Fresh tissue from animals in set A were stained for OX-42 and glial fibrillary acidic protein (GFAP) as previously described (18) (supplemental methods).

To assess the extent of the microglial activation, the number of OX42-positive cells in both the striatum and the cortex was counted. Three photomicrographs (area, $399.7 \times 258.2 \mu \mathrm{m}$ ) from randomly chosen fields of view from bregma +1.0AP were obtained. The total cell count per $\mathrm{mm}^{2}$ was calculated for each field of view in a masked fashion and then averaged to obtain an average cell count per unit area. 
This average was then multiplied by the slice thickness for each brain region. This analysis was performed on animals imaged with ${ }^{11} \mathrm{C}-(R)$ PK11195 (10 $\mu \mathrm{g}$ of LPS, $n=3$; $1 \mu \mathrm{g}$ of LPS, $n=3$; saline, $n=3)$ and ${ }^{18} \mathrm{~F}-\mathrm{GE}-180$ (10 $\mu \mathrm{g}$ of LPS, $n=3 ; 1 \mu \mathrm{g}$ of LPS, $n=3$; saline, $n=3$ ).

\section{Statistical Analysis}

Prism (5.01; Graph Pad Software Inc.) was used for any statistical analysis and the outcome was considered significant if the $P$ value was less than 0.05 . Autoradiography and immunohistochemistry images were manually coregistered with Photoshop (CS4, Adobe) to resize and overlay the images using neuroanatomic landmarks such as the ventricles.

\section{RESULTS}

PK11195 and GE-180 were successfully labeled with the shortlived radioactive isotopes ${ }^{11} \mathrm{C}$ and ${ }^{18} \mathrm{~F}$, respectively, and this labeling was confirmed by radio-high-performance liquid chromatography (Fig. 1; more information is provided in the supplemental results).

\section{Ex Vivo Autoradiography}

The intrastriatal injection of LPS in set A animals caused widespread neuroinflammation in the injected hemisphere and activation of the microglia. This activation was observed by the uptake of both ${ }^{11} \mathrm{C}-(R)$-PK11195 and ${ }^{18} \mathrm{~F}-\mathrm{GE}-180$ in the images obtained from the digital autoradiography (Fig. 2A). Increased radiotracer binding was observed in animals injected with either $10 \mu \mathrm{g}$ of LPS (Fig. $2 \mathrm{~A}, \mathrm{BP}_{\text {ex vivo }}=0.76 \pm 0.31$ for ${ }^{11} \mathrm{C}-\mathrm{PK} 11195$ and $1.32 \pm$ 0.13 for ${ }^{18} \mathrm{~F}-\mathrm{GE}-180$ ) or $1 \mu \mathrm{g}$ of LPS (Fig. $2 \mathrm{~A}, \mathrm{BP}_{\text {ex vivo }}=0.67 \pm$ 0.30 for ${ }^{11} \mathrm{C}-\mathrm{PK} 11195$ and $1.33 \pm 0.17$ for $\left.{ }^{18} \mathrm{~F}-\mathrm{GE}-180\right)$ but not in animals injected with saline (Fig. $2 \mathrm{~A}, \mathrm{BP}_{\text {ex vivo }}=0.05 \pm 0.02$ for ${ }^{11} \mathrm{C}$-PK11195 and $0.05 \pm 0.01$ for $\left.{ }^{18} \mathrm{~F}-\mathrm{GE}-180\right)$. In the animals injected with $10 \mu \mathrm{g}$ of LPS, a halo of increased binding was observed around the injection site, which was not observed in animals injected with $1 \mu \mathrm{g}$ of LPS.

The repeated-measures ANOVA on the binding potentials obtained from the ROI analysis performed on the autoradiography images showed that there was a significant main effect of LPS treatment $\left(\mathrm{F}_{2,12}=16.40, P=0.0004\right)$. In addition, there was a significant main effect $\left(\mathrm{F}_{2,12}=6.45, P=0.0260\right)$ in which the binding potential of ${ }^{18} \mathrm{~F}-\mathrm{GE}-180$ was greater than that of ${ }^{11} \mathrm{C}-(R)-$ PK11195 (Fig. 2B). When Bonferroni post hoc analysis was used, only the animals injected with LPS at either concentration, and imaged with ${ }^{18} \mathrm{~F}-\mathrm{GE}-180$, showed a significant increase in radiotracer binding in the ipsilateral hemisphere $(P<0.01)$, compared with the saline-injected group (Fig. 2B). To determine the use of the contralateral hemisphere as a reference region, we compared the BR between the contralateral striatum and the cerebellum between the different groups. There was no significant difference $(P=0.106)$ between brain regions distal to the LPS injection in the binding of ${ }^{11} \mathrm{C}-(R)-\mathrm{PK} 11195(10 \mu \mathrm{g}, \mathrm{BR}=0.79 \pm 0.04 ; 1 \mu \mathrm{g}$, $\mathrm{BR}=0.92 \pm 0.12)$ when compared with the saline control group $(\mathrm{BR}=0.74 \pm 0.04)$ (Fig. 2C).

\section{Selectivity of Radiotracers}

To assess whether ${ }^{11} \mathrm{C}-(R)-\mathrm{PK} 11195$ and ${ }^{18} \mathrm{~F}-\mathrm{GE}-180$ are binding to the same cell type within the central nervous system, we quantified the increase in expression of OX-42, a marker of activated microglia, which are considered to be the major source of TSPO binding in the central nervous system (5). Repeated-measures ANOVA analysis performed on the counts of OX-42-positive cells demonstrated that there was a significant main effect of LPS treatment in both the striatum $\left(\mathrm{F}_{2,18}=146.725, P<0.0001\right.$, Fig. $\left.3 \mathrm{~A}\right)$

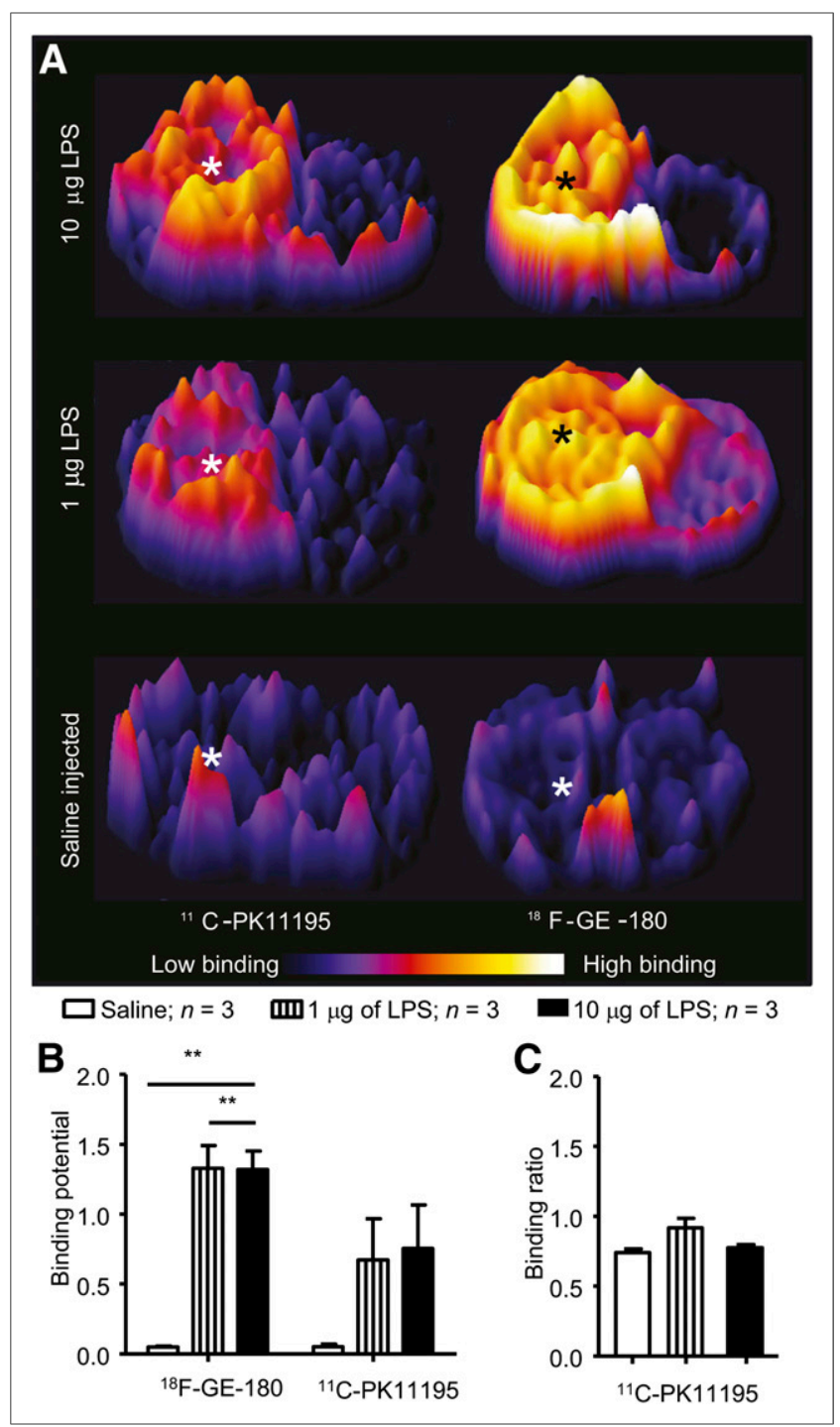

FIGURE 2. LPS causes unilateral upregulation of TSPO binding of ${ }^{11} \mathrm{C}$ (R)-PK11195 and ${ }^{18} \mathrm{~F}-\mathrm{GE}-180$. (A) Representative coronal striatal images obtained when animals were imaged with ${ }^{11} \mathrm{C}-(R)$-PK11195 or ${ }^{18} \mathrm{~F}-\mathrm{GE}-$ 180. ${ }^{*}=$ injection site. (B) Autoradiography analysis reveals significant $\left({ }^{*} P<0.01\right)$ increase in ${ }^{18} \mathrm{~F}-\mathrm{GE}-180$ binding after intracerebral injection of LPS $(10$ or $1 \mu \mathrm{g})$; similar significant increase was not observed with ${ }^{11} \mathrm{C}-(R)-\mathrm{PK} 11195$. Unprocessed images are shown in Supplemental Fig. 3C. There is no significant increase $(P=0.106)$ in signal in contralateral hemisphere, using cerebellum as reference region. Bars $=$ SEM.

and the cortex $\left(\mathrm{F}_{2,18}=269.86, P<0.0001\right.$, Fig. 3A $)$. In the striatum, there was no difference observed between the groups imaged with ${ }^{11} \mathrm{C}-(R)-\mathrm{PK} 11195$ or ${ }^{18} \mathrm{~F}-\mathrm{GE}-180(P=0.179)$. However, in the cortex there was a significant main effect of LPS treatment observed between the groups imaged with ${ }^{11} \mathrm{C}-(R)$-PK11195 or ${ }^{18} \mathrm{~F}-\mathrm{GE}-$ $180\left(\mathrm{~F}_{1,18}=9.086, P=0.011\right.$, Fig. $\left.3 \mathrm{~A}\right)(P=0.02)$. Bonferroni post hoc analysis revealed that, in the striatum there was a highly significant increase in OX-42-positive cells after an injection of LPS (10 or $1 \mu \mathrm{g}, P<0.0001$, Fig. 3A). However, there was no significant difference between the animals injected with $10 \mu \mathrm{g}$ of LPS, compared with the animals injected with $1 \mu \mathrm{g}$ of LPS $(P=1)$. In the cortex, post hoc analysis demonstrated that the injection of LPS (10 or $1 \mu \mathrm{g}$ ) caused a highly significant increase in OX$42-$ positive cells $(P<0.0001)$. In addition to this, there was also 


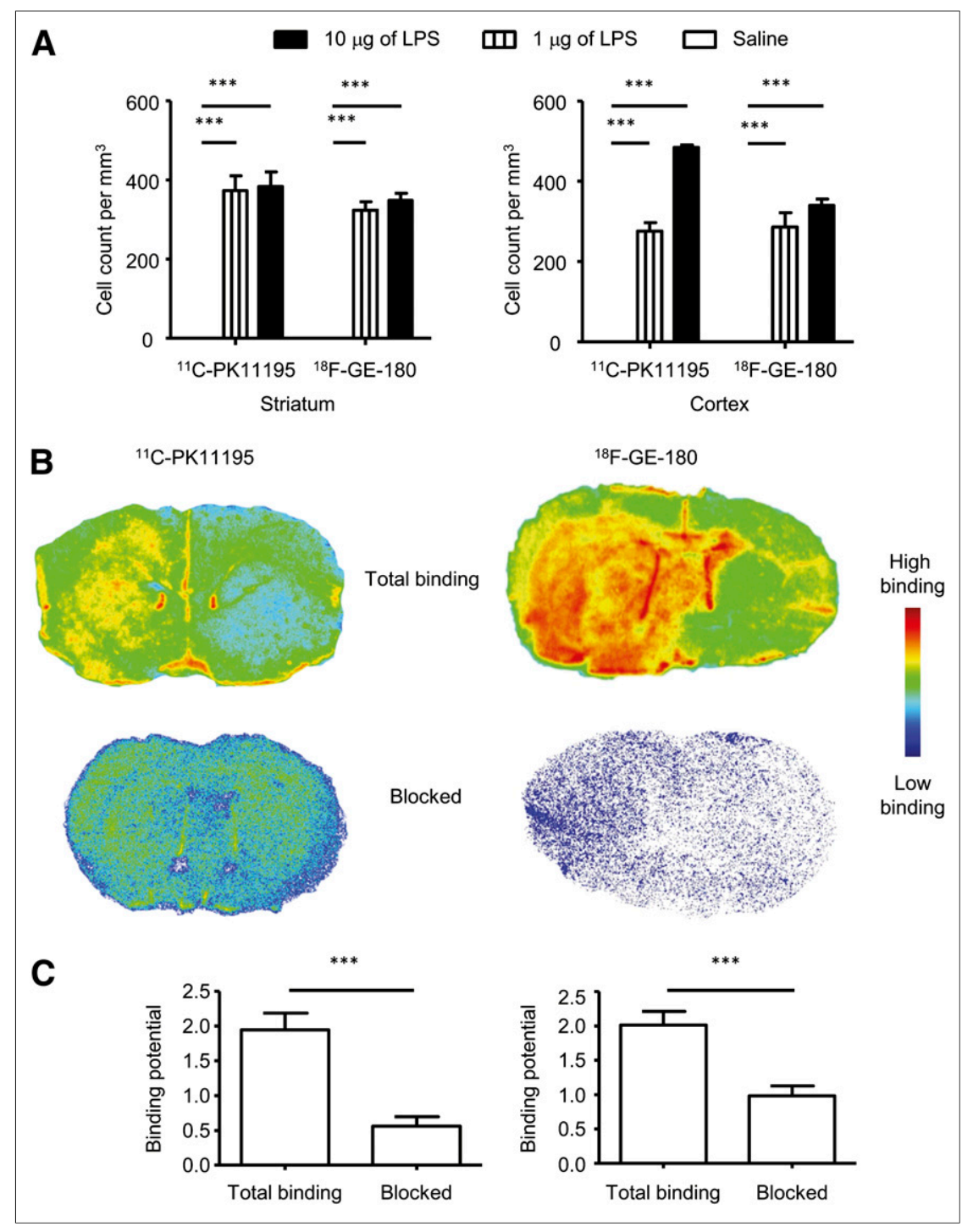

FIGURE 3. Selectivity of ${ }^{11} \mathrm{C}-(R)-\mathrm{PK} 11195$ and ${ }^{18} \mathrm{~F}-\mathrm{GE}-180$. (A) Intracerebral injection of LPS causes significant increase in OX-42-positive cells in striatum and cortex in injected hemisphere $(P<0.0001)$ when compared with control group. There was no significant difference between animals imaged with ${ }^{18} \mathrm{~F}-\mathrm{GE}-180$, compared with ${ }^{11} \mathrm{C}-(R)-\mathrm{PK} 11195$, or animals injected with $10 \mu \mathrm{g}$ of LPS, compared with $1 \mu \mathrm{g} .{ }^{\star \star \star} P<0.0001 .{ }^{11} \mathrm{C}-(R)-\mathrm{PK} 11195$ and ${ }^{18} \mathrm{~F}-\mathrm{GE}-180$ bind specifically to same target in vitro. (B) Representative in vitro autoradiography images from coronal striatal sections demonstrating total binding of ${ }^{11} \mathrm{C}-(R)-P K 11195$ and ${ }^{18} \mathrm{~F}-\mathrm{GE}-180$ and reduction in signal when ${ }^{11} \mathrm{C}-(R)-\mathrm{PK} 11195$ signal was blocked by GE-180 or vice versa. (C) GE-180 significantly reduces $(P<0.0001)$ specific signal observed when using ${ }^{11} \mathrm{C}-(R)-\mathrm{PK} 11195$ to image the increase in TSPO expression. Correspondingly, $(R)$-PK11195 significantly $(P<0.0001)$ reduces specific signal observed when using ${ }^{18} \mathrm{~F}-\mathrm{GE}-180$ as radiotracer. Bars $=\mathrm{SEM}$.

a significant increase in OX-42-positive cells after an injection of $10 \mu \mathrm{g}$ of LPS, compared with an injection of $1 \mu \mathrm{g}$ of LPS $(P<$ 0.0001). After an injection of LPS into the left striatum, there was also a statistically significant difference between the number of OX-42-positive cells in the injected hemisphere, compared with the contralateral hemisphere (data not shown, $P<0.0001$ ). In vitro blocking studies revealed a reduction in specific binding of both ${ }^{11} \mathrm{C}-(R)$-PK11195 and ${ }^{18} \mathrm{~F}$-GE-180 when either was blocked by the corresponding nonradioactive tracer (Fig. 3B). Analysis of the ROI means showed a significant reduction (Student $t$ test, $P<$ $0.0001)$ in the binding potential when ${ }^{11} \mathrm{C}-(R)-\mathrm{PK} 11195$ was blocked with nonradioactive GE-180 (Fig. 3C). A similar significant reduction (Student $t$ test, $P<0.0005)$ was observed in the binding potential when ${ }^{18} \mathrm{~F}-\mathrm{GE}-180$ was blocked with nonradioactive PK11195 (Fig. 3C). To confirm that the administration of tracer had no impact on the histopathology, we counted the number of OX-42-positive cells. In the striatum, there was no significant difference in the number of OX-42positive cells in the animals imaged with ${ }^{18} \mathrm{~F}-\mathrm{GE}-180$ or ${ }^{11} \mathrm{C}-(R)$-PK11195. There was a small increase in OX-42-positive cells in the cortex in the ${ }^{11} \mathrm{C}-(R)-\mathrm{PK} 11195$ group, compared with animals imaged with ${ }^{18} \mathrm{~F}$ GE-180 (Fig. 3A), but the binding potential was decreased in the ${ }^{11} \mathrm{C}-(R)$-PK11195 group, further highlighting the improved imaging with ${ }^{18} \mathrm{~F}-\mathrm{GE}-180$.

\section{Specificity of Radiotracers}

To determine the specificity of the 2 radiotracers, we compared the areas of OX42 staining (Fig. 4) and increased GFAP immunoreactivity (Fig. 4) to the extent of binding observed in the autoradiography. The area of microglial activation corresponded to the area of increased binding observed in the autoradiography for both ${ }^{18}$ F-GE-180 (Fig. 4) and ${ }^{11} \mathrm{C}-(R)-$ PK11195 (data not shown). There was no corresponding increase in microglial activation observed in the contralateral hemisphere or the animals injected with saline (data not shown). There was also a smaller area of increased expression of GFAP (Fig. 4). Where there was an increase in immunoreactivity of GFAP, there was a corresponding increase in the signal from the autoradiography (Fig. 4).

\section{In Vivo Imaging}

From the in vivo PET images, of the animals in set $\mathrm{B}$, it was possible to observe an increased binding of both ${ }^{11} \mathrm{C}-(R)$ PK11195 and ${ }^{18} \mathrm{~F}-\mathrm{GE}-180$ in the injected striatum (Figs. 5A and 5B). The binding potential $\left(\mathrm{BP}_{\text {in vivo }}\right)$ was calculated over the time of maximal binding (25-50 min, supplemental results and Supplemental Fig. 2). The $\mathrm{BP}_{\text {in }}$ vivo analysis revealed a significant increase $\left(\mathrm{F}_{4}=\right.$ 58.08, $P<0.001)$ in the animals injected with $10 \mu \mathrm{g}$ of LPS $\left(\mathrm{BP}_{\text {in vivo }}=0.47 \pm 0.06\right.$ for ${ }^{11} \mathrm{C}-\mathrm{PK} 11195$ and $0.92 \pm 0.07$ for $\left.{ }^{18} \mathrm{~F}-\mathrm{GE}-180\right)$, compared with the animals injected with saline $\left(\mathrm{BP}_{\text {in vivo }}=0.00 \pm 0.07\right.$ for ${ }^{11} \mathrm{C}-\mathrm{PK} 11195$ and $0.00 \pm 0.01$ for ${ }^{18} \mathrm{~F}-\mathrm{GE}-180$, Fig. 5C). There was also a significant increase $(P<0.01)$ in the $\mathrm{BP}_{\text {in vivo }}$ from the animals injected with $10 \mu \mathrm{g}$ of LPS when the images were acquired with ${ }^{18} \mathrm{~F}-\mathrm{GE}-180$, compared with those acquired with ${ }^{11} \mathrm{C}-(R)-\mathrm{PK} 11195$ (Fig. 5C). From the 3-dimensional pixelwise modeling, the area of ${ }^{18} \mathrm{~F}-\mathrm{GE}-180$ binding was increased, compared with ${ }^{11} \mathrm{C}-(R)-\mathrm{PK} 11195$ (Figs. 5A and 5B). 


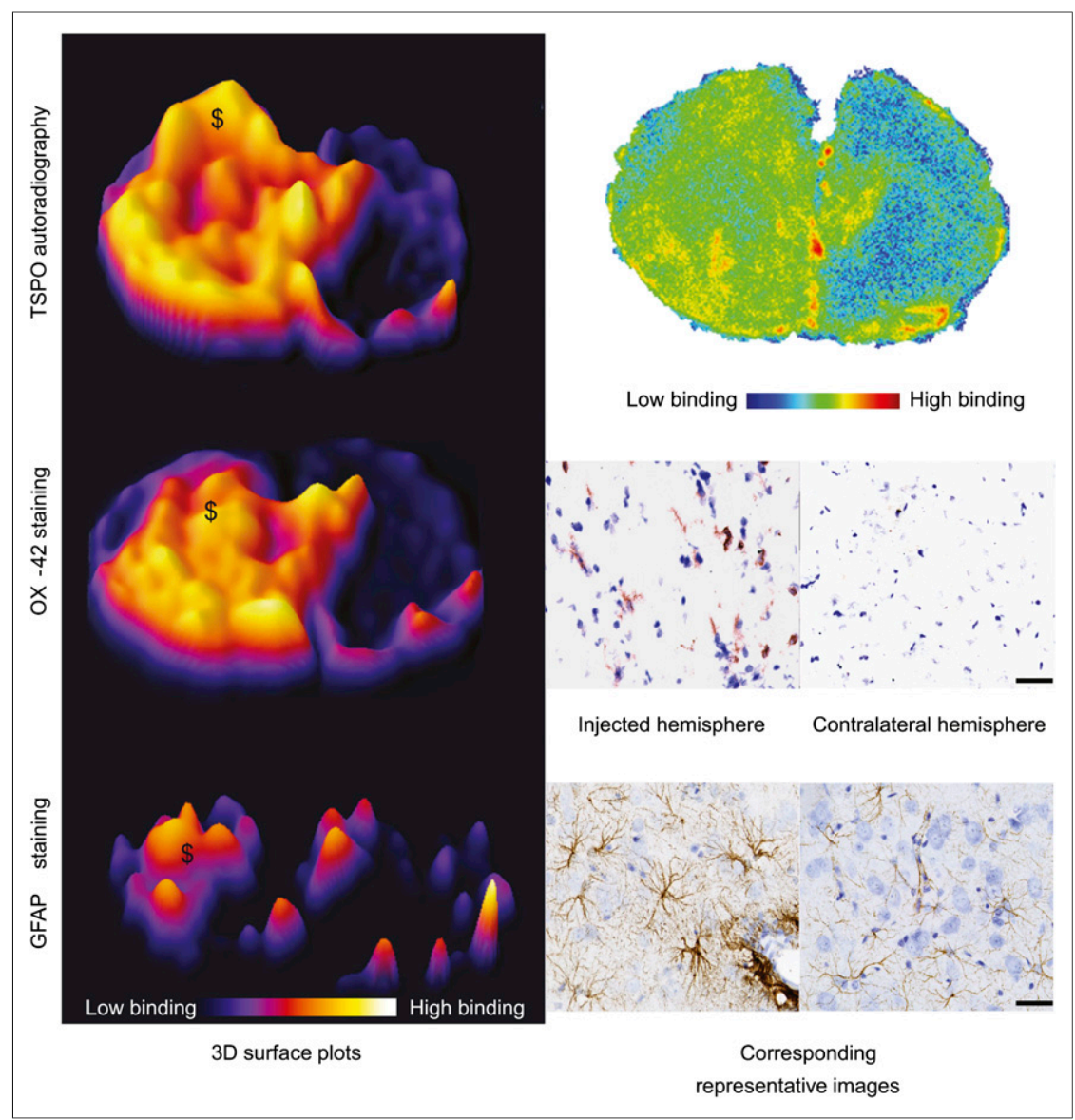

FIGURE 4. Specificity studies; histologic comparison to autoradiography results. (Left) Threedimensional surface plots demonstrate area of increased signal observed in autoradiography from animals imaged with ${ }^{18} \mathrm{~F}-\mathrm{GE}-180$ and increase in OX-42 and GFAP immunoreactivity in sequential sections. (Right) Shown are corresponding images or high powered photomicrographs from injection site obtained from ${ }^{18} \mathrm{~F}-\mathrm{GE}-180$ autoradiography, OX-42 (activated microglia), and GFAP (astrocytes) staining. \$ marks increase in autoradiography signal where there is corresponding area of OX-42-positive cells and increased GFAP immunoreactivity. Scale bar $=50 \mu \mathrm{m}$.

\section{DISCUSSION}

Data presented here demonstrate for the first time that the novel radiotracer ${ }^{18} \mathrm{~F}-\mathrm{GE}-180$ is superior to ${ }^{11} \mathrm{C}-(R)$-PK11195 in detecting in vivo glial activation in our rodent model of neuroinflammation. The superiority of the tracer was apparent both in ex vivo and in vivo imaging techniques, for which ${ }^{18} \mathrm{~F}-\mathrm{GE}-180$ had a statistically significant higher binding potential when compared with ${ }^{11} \mathrm{C}-(R)-\mathrm{PK} 11195$. The area of TSPO binding colocalized with the area of microglial activation after an intrastriatal injection of LPS. However, the intensity of the TSPO signal increased in the presence of both activated microglial cells and reactive astrocytes.

We used an intrastriatal injection of LPS to induce unilateral acute inflammation and glial activation within the rodent brain, which provides a reliable and reproducible inflammatory response throughout adulthood (21). The main benefit of the model used in this paper is that it causes a unilateral inflammatory response, permitting an internal control for the PET modeling and avoiding the need for serial blood sampling, which would be required if no reference region was available (22). In addition to this, high binding of both tracers within the myocardium prevents the use of the left ventricle as an internal blood input function (23).
Several other models have been used to compare TSPO ligands (9). The intrastriatal injection of $\alpha$-amino-3-hydroxy-5-methyl4-isoxazolepropionic has been used in several studies (24-26) and was used primarily to study the effect of excitotoxity on glial activation (27). The pathology is associated with considerable cell death (28), which could be considered a confound, and maximal activation of the microglia and astrocytes occurs after $7 \mathrm{~d}$ (26). The LPS injection does not cause any significant cell death (11). LPS, on binding to LPS binding protein and CD14, quickly activates the immune system via toll-like receptor 4 (29) and the NFKB pathway (30) to induce an M1 phenotype (31). This model has also been used in the past to show the different binding characteristics of TSPO ligands (32) and has the advantage over the $\alpha$-amino3-hydroxy-5-methyl-4-isoxazolepropionic model that the animals can be imaged at a much earlier time point and it does not induce overt clinical signs.

We also observed an area of increased GFAP immunoreactivity after the LPS injection. The area of increased immunoreactivity of GFAP varied in the model but was always considerably smaller than the area of OX-42 activation. It has been suggested that it takes longer for astrocytes to become fully activated after brain injury, but TSPO ligands do display increased binding to activated astrocytes (33), and to fully probe the interaction of astrocytes with the TSPO ligands imaging at a later time point, such as at 3-7 d, might be useful. However, the results presented here suggest that the TSPO signal is the sum total of the increase in TSPO expression in both the microglia and the astrocytes where the binding coincides. This does not diminish the use of TSPO as a surrogate marker of neuroinflammation where the activation of both populations is usual. However, attributing the signal to one specific cell type must be done with caution.

In addition to the increase in TSPO expression observed in the presence of both activated microglia and astrocytes, there was binding of the radiotracers in the ventricular area and the olfactory bulbs, even in the saline-injected animals, suggesting that the tracer is binding to further cell types in these areas. This fact has previously been used to validate TSPO tracers in healthy animals (10). Previously, it has been reported that the TSPO protein is also expressed in the ependymal cells (34) and cells within the choroid plexus $(9,35)$. Additionally, the binding in the olfactory bulbs in rodents has previously been observed (36). The causes for this binding remain unclear, with several reports suggesting that neuronal cells in this brain region express TSPO in neo-natal rats (35) and humans (37). It has been suggested that there is an activation of the microglial cells thought to be caused by the replacement of the granular and periglomerular neurons from the subventricular zone (38). It has been shown that experimental autoimmune encephalomyelitis enhances this cellular migration and can be seen by an increase in TSPO binding (39). 


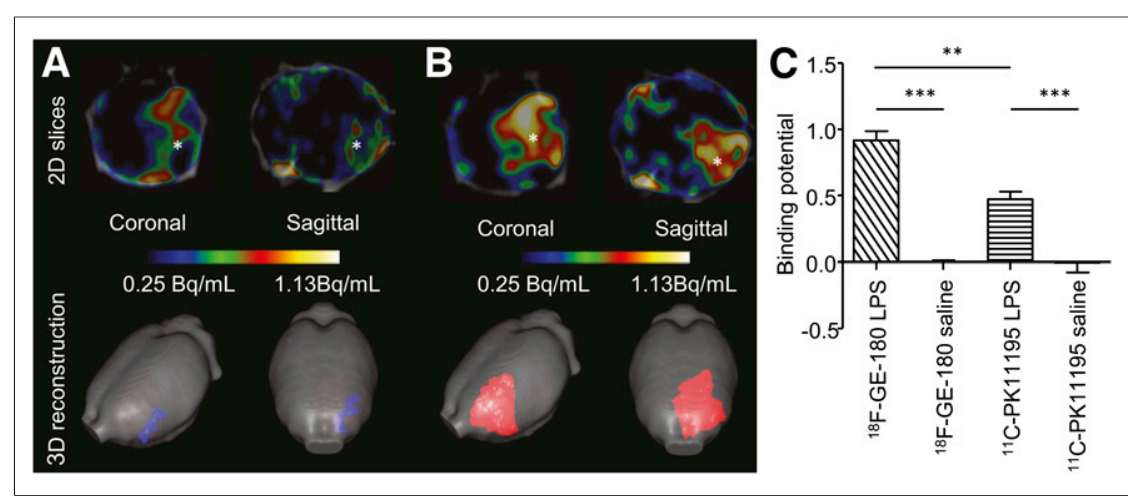

FIGURE 5. Radiotracer ${ }^{18} \mathrm{~F}-\mathrm{GE}-180$ is superior to ${ }^{11} \mathrm{C}-(R)-\mathrm{PK} 11195$ in detection of TSPO upregulation after brain injury. (A) Averaged $(n=3)$ normalized (bound-to-free pixelwise modeling) images from animals imaged in vivo with ${ }^{11} \mathrm{C}-(R)-\mathrm{PK} 11195$. (B) Corresponding images using ${ }^{18} \mathrm{~F}$ GE-180. PET/CT 2-dimensional slices at level of striatum show increase in signal at site of injury (shown by *). 3-dimensional reconstruction demonstrates greater area, which can be segmented when imaging is performed with ${ }^{18} \mathrm{~F}-\mathrm{GE}-180$. (C) Quantification of binding demonstrates that there is significant increase in binding of both ${ }^{11} \mathrm{C}-(R)$-PK11195 $(P<0.0001)$ and ${ }^{18} \mathrm{~F}-\mathrm{GE} 180(P<0.0001)$ after injection of LPS $(10 \mu \mathrm{g})$ into left striatum, compared with animals injected with saline. There is significantly $(P<0.01)$ higher binding of ${ }^{18} \mathrm{~F}-\mathrm{GE}-180$, compared with ${ }^{11} \mathrm{C}-(R)-\mathrm{PK} 11195$ in animals injected with LPS $(10 \mu \mathrm{g})$. Bars $=$ SEM

\section{CONCLUSION}

This study reveals that ${ }^{18} \mathrm{~F}-\mathrm{GE}-180$ is a promising new PET radiotracer for imaging the increase in TSPO expression in response to neuroinflammation. ${ }^{18} \mathrm{~F}-\mathrm{GE}-180$ performed significantly better than the current gold standard ${ }^{11} \mathrm{C}-(R)$-PK11195 radiotracer for imaging this target by displaying improved binding potentials both ex vivo and in vivo.

\section{DISCLOSURE}

The costs of publication of this article were defrayed in part by the payment of page charges. Therefore, and solely to indicate this fact, this article is hereby marked "advertisement" in accordance with 18 USC section 1734. This study is funded in part by the Academy of Finland; Biocentre Finland; GE Healthcare, Ltd.; and European Union's Seventh Framework Program (FP7/2007-2013) under grant agreement HEALTH-F2-2011-278850 (INMiND). No other potential conflict of interest relevant to this article was reported.

\section{ACKNOWLEDGMENTS}

We thank Elisa Riuttala, Markko Vehmanen, and Merja Tuomas from the Turku PET Centre for their assistance. We also thank the staff of the radiopharmaceutical chemistry laboratory at the Turku PET Centre.

\section{REFERENCES}

1. Zipp F, Aktas O. The brain as a target of inflammation: common pathways link inflammatory and neurodegenerative diseases. Trends Neurosci. 2006;29: 518-527.

2. Lavisse S, Guillermier M, Hérard AS, et al. Reactive astrocytes overexpress TSPO and are detected by TSPO positron emission tomography imaging. J Neurosci. 2012;32:10809-10818.

3. Papadopoulos V, Baraldi M, Guilarte TR, et al. Translocator protein (18-kDa): new nomenclature for the peripheral-type benzodiazepine receptor based on its structure and molecular function. Trends Pharmacol Sci. 2006;27:402-409.

4. Benavides J, Fage D, Carter C, Scatton B. Peripheral type benzodiazepine binding sites are a sensitive indirect index of neuronal damage. Brain Res. 1987;421: $167-172$.
5. Chen MK, Guilarte TR. Translocator protein 18$\mathrm{kDa}$ (TSPO): molecular sensor of brain injury and repair. Pharmacol Ther. 2008;118:1-17.

6. Banati RB. Visualising microglial activation in vivo. Glia. 2002;40:206-217.

7. Ching ASC, Kuhnast B, Damont A, Roeda D, Tavitian B, Dollé F. Current paradigm of the $18-\mathrm{kDa}$ translocator protein (TSPO) as a molecular target for PET imaging in neuroinflammation and neurodegenerative diseases. Insights Imaging. 2012:1-9.

8. Imaizumi M, Kim H-J, Zoghbi SS, et al. PET imaging with ${ }^{11} \mathrm{C}-\mathrm{PBR} 28$ can localize and quantify upregulated peripheral benzodiazepine receptors associated with cerebral ischemia in rat. Neurosci Lett. 2007;411:200-205.

9. Chauveau F, Boutin H, Van Camp N, Dollé F, Tavitian B. Nuclear imaging of neuroinflammation: a comprehensive review of ${ }^{11} \mathrm{C}-\mathrm{PK} 11195$ challengers. Eur J Nucl Med Mol Imaging. 2008;35: 2304-2319.

10. Wadsworth H, Jones PA, Chau W-F, et al. ${ }^{18} \mathrm{~F}-\mathrm{GE}-$ 180: A novel fluorine-18 labelled PET tracer for imaging translocator protein $18 \mathrm{kDa}$ (TSPO). Bioorg Med Chem Lett. 2012;22:1308-1313.

11. Couch Y, Alvarez-Erviti L, Sibson NR, Wood MJA, Anthony DC. The acute inflammatory response to intranigral a-synuclein differs significantly from intranigral lipopolysaccharide and is exacerbated by peripheral inflammation. J Neuroinflammation. 2011;8:166.

12. Depino AM, Earl C, Kaczmarczyk E, et al. Microglial activation with atypical proinflammatory cytokine expression in a rat model of Parkinson's disease. Eur J Neurosci. 2003; 18:2731-2742.

13. Venneti S, Lopresti BJ, Wiley CA. The peripheral benzodiazepine receptor (translocator protein $18 \mathrm{kDa}$ ) in microglia: from pathology to imaging. Prog Neurobiol. 2006;80:308-322.

14. Kuhlmann AC, Guilarte TR. Cellular and subcellular localization of peripheral benzodiazepine receptors after trimethyltin neurotoxicity. J Neurochem. 2000;74: 1694-1704.

15. Hashimoto K, Inoue O, Suzuki K, Yamasaki T, Kojima M. Synthesis and evaluation of ${ }^{11} \mathrm{C}$-PK11195 for in vivo study of peripheral-type benzodiazepine receptors using position emission tomography. Ann Nucl Med. 1989;3:63-71.

16. Shah F, Hume SP, Pike VW, Ashworth S, McDermott J. Synthesis of the enantiomers of [ $N$-methyl- ${ }^{11} \mathrm{C}$-PK 11195 and comparison of their behaviours as radioligands for PK binding sites in rats. Nucl Med Biol. 1994;21:573-581.

17. Caporale V, Alessandrini B, Villa P, Del Papa S. Global perspectives on animal welfare: Europe. Rev Sci Tech. 2005;24:567.

18. Serres S, Anthony DC, Jiang Y, et al. Comparison of MRI signatures in pattern I and II multiple sclerosis models. NMR Biomed. 2009;22:1014-1024.

19. Forsback S, Niemi R, Marjamäki P, et al. Uptake of $6-{ }^{18}$ F-fluoro-L-dopa and ${ }^{18} \mathrm{~F}$ CFT reflect nigral neuronal loss in a rat model of Parkinson's disease. Synapse. 2004;51:119-127.

20. Farde L, Eriksson L, Blomquist G, Halldin C. Kinetic analysis of central ${ }^{11} \mathrm{C}$ raclopride binding to D2-dopamine receptors studied by PET: a comparison to the equilibrium analysis. J Cereb Blood Flow Metab. 1989;9:696-708.

21. Campbell SJ, Carare-Nnadi R, Losey P, Anthony D. Loss of the atypical inflammatory response in juvenile and aged rats. Neuropathol Appl Neurobiol. 2007;33:108-120.

22. Logan J. Graphical analysis of PET data applied to reversible and irreversible tracers. Nucl Med Biol. 2000;27:661-670.

23. Iida H, Rhodes CG, de Silva R, et al. Use of the left ventricular time-activity curve as a noninvasive input function in dynamic oxygen-15-water positron emission tomography. J Nucl Med. 1992;33:1669-1677.

24. Chauveau F, Boutin H, Van Camp N, et al. In vivo imaging of neuroinflammation in the rodent brain with ${ }^{11} \mathrm{C}$ - SSR180575, a novel indoleacetamide radioligand of the translocator protein (18 kDa). Eur J Nucl Med Mol Imaging. 2011;38: 509-514.

25. Chauveau F, Van Camp N, Dollé F, et al. Comparative evaluation of the translocator protein radioligands ${ }^{11} \mathrm{C}$-DPA-713, ${ }^{18} \mathrm{~F}-\mathrm{DPA}-714$, and ${ }^{11} \mathrm{C}-\mathrm{PK} 11195$ in a rat model of acute neuroinflammation. $J$ Nucl Med. 2009;50:468-476.

26. Boutin $\mathrm{H}$, Chauveau $\mathrm{F}$, Thominiaux $\mathrm{C}$, et al. In vivo imaging of brain lesions with ${ }^{11} \mathrm{C}$-CLINME, a new PET radioligand of peripheral benzodiazepine receptors. Glia. 2007;55:1459-1468. 
27. Cuthill DJ, Fowler JH, McCulloch J, Dewar D. Different patterns of axonal damage after intracerebral injection of malonate or AMPA. Exp Neurol. 2006; 200:509-520.

28. Parfenova H, Tcheranova D, Basuroy S, Fedinec AL, Liu J, Leffler CW. Functional role of astrocyte glutamate receptors and carbon monoxide in cerebral vasodilation response to glutamate. Am J Physiol Heart Circ Physiol. 2012;302: H2257-H2266.

29. Bsibsi M, Ravid R, Gveric D, Van Noort JM. Broad expression of toll-like receptors in the human central nervous system. J Neuropathol Exp Neurol. 2002; $61: 1013$.

30. Pålsson-McDermott EM, O'Neill LAJ. Signal transduction by the lipopolysaccharide receptor, toll-like receptor-4. Immunology. 2004;113:153-162.

31. Cunningham C. Microglia and neurodegeneration: the role of systemic inflammation. Glia. 2013;61:71-90.

32. Venneti S, Lopresti BJ, Wang G, et al. A comparison of the high-affinity peripheral benzodiazepine receptor ligands DAA1106 and (R)-PK11195 in rat models of neuroinflammation: implications for PET imaging of microglial activation. J Neurochem. 2007;102:2118-2131.

33. Seneca N. Recent advances in positron emission tomography imaging of brain. Drugs Future. 2011;36:601.
34. Cosenza-Nashat M, Zhao ML, Suh HS, et al. Expression of the translocator protein of $18-\mathrm{kDa}$ by microglia, macrophages and astrocytes based on immunohistochemical localization in abnormal human brain. Neuropathol Appl Neurobiol. 2009;35:306-328.

35. Anholt RR, De Souza EB, Oster-Granite ML, Snyder SH. Peripheral-type benzodiazepine receptors: autoradiographic localization in whole-body sections of neonatal rats. J Pharmacol Exp Ther. 1985;233:517-526.

36. Zhang M-R, Kumata K, Maeda J, et al. ${ }^{11} \mathrm{C}-\mathrm{AC}-5216$ : a novel PET ligand for peripheral benzodiazepine receptors in the primate brain. J Nucl Med. 2007;48: 1853-1861.

37. Rupprecht R, Papadopoulos V, Rammes G, et al. Translocator protein (18-kDa) (TSPO) as a therapeutic target for neurological and psychiatric disorders. Nat Rev Drug Discov. 2010;9:971-988.

38. Mattner F, Staykova M, Berghofer P, et al. Central nervous system expression and PET imaging of the translocator protein in relapsing: remitting experimental autoimmune encephalomyelitis. J Nucl Med. 2013;54:291-298.

39. Picard-Riera N, Decker L, Delarasse C, et al. Experimental autoimmune encephalomyelitis mobilizes neural progenitors from the subventricular zone to undergo oligodendrogenesis in adult mice. Proc Natl Acad Sci USA. 2002;99:1321113216. 